\title{
Welfare assessment of suckling goat kids subjected to a nutritional trial
}

\author{
Avaliação do bem-estar de cabritos em aleitamento submetidos a um \\ experimento nutricional
}

Daiana de Oliveira ${ }^{1^{*}}$, Izabelle Auxiliadora Molina de Almeida Teixeira², Samuel Figueiredo de Souza ${ }^{3}$, Kleber Tomás de Resende ${ }^{2}$

${ }^{1}$ Department of Animal Environment and Health, Swedish University of Agricultural Sciences (SLU), Uppsala, Sweden

${ }^{2}$ Department of Animal Science, Universidade Estadual Paulista (UNESP), Jaboticabal, SP, Brazil

${ }^{3}$ Embrapa - Brazilian Agricultural Research Corporation, Aracaju, SE, Brazil

\begin{abstract}
Many animals are subjected to experimental trials which impose some kind of physical and psychological suffering, and some of those methodologies are still used in nutritional experiments. Our purpose was to evaluate the welfare of suckling goat kids in a nutritional trial when submitted to feed restriction and housed in metabolic cages. Firstly a circadian rhythm trial was conducted to assess the behavior rhythm of goat kids under these conditions. Following this study, behavioral observations were conducted with the ongoing nutrition experiment. Direct observations with continuous recording were carried out with 27 Saanen goat kids (male, female and castrated males), submitted to three nutritional regimes $(0 \%, 24.3 \%$ and $52.3 \%$ of feed restriction). Feed consumption was daily controlled and body weight was measured at birth and weekly until 5 weeks of age. All animals presented stereotypes, however female kids bit the bars more often $(p=0.04)$ and for longer time $(p=0.0094)$ than other animals. Goat kids under severe feed restriction presented reduced reaction
\end{abstract}

to humans ( $\mathrm{p}=0.03$ ), standing still for longer periods and presented signals of learned helplessness. This study showed that goat kids' welfare was compromised during the nutritional experiment. New approaches within nutritional science research are highly encouraged, in order to keep the welfare integrity of animals used in research.

Keywords: Behavior. Goats. Nutrition. Digestibility. Metabolic cage.

\section{Resumo}

Muitos animais são submetidos a experimentos científicos que impõem algum tipo de sofrimento físico e psicológico, e algumas dessas metodologias ainda são usadas em experimentos nutricionais. Nosso objetivo foi avaliar o bem-estar de cabritos em aleitamento, em um estudo de nutrição, quando submetidos à restrição alimentar 
e alojados em gaiolas metabólicas. Primeiramente, um estudo do ritmo circadiano comportamental foi realizado. Em seguida, observações diretas e contínuas foram realizadas utlizando 27 cabritos Saanen (machos, fêmeas e castrados), submetidos a três regimes nutricionais (0\%, $24,3 \%$ e $52,3 \%$ de restrição alimentar). O consumo de alimento foi controlado diariamente e o peso corporal foi medido no momento do nascimento até 5 semanas de idade. Todos os animais apresentaram estereotipias, entretanto as fêmeas morderam as barras mais vezes $(p=0,04) e$ durante mais tempo $(p=0,0094)$ do que os outros animais. Cabritos sob restrição alimentar severa apresentaram redução de reação aos humanos $(p=0,03)$, permaneceram em pé por períodos mais longos e apresentaram sinais de desesperança aprendida. Este estudo mostrou que o bem-estar dos cabritos foi comprometido durante o experimento de nutrição. Novas abordagens no âmbito da investigação científica na nutrição animal são altamente recomendadas, a fim de manter a integridade do bemestar de animais utilizados em pesquisas.

Palavras-chave: Comportamento. Caprinos. Nutrição. Digestibilidade. Gaiola metabólica.

\section{Introduction}

In the last decades, the use of animals in science has been criticized for several reasons, mostly due to physical and psychological suffering. From a welfare perspective, three fundamental elements are critical: 1) normal biological functioning (ensuring good health, growth, and reproduction), 2) emotional state (animals should be raised in ways to minimize suffering and promote contentment), 3) natural living (i.e., ability to express natural behaviors) (Fraser et al., 1997).

Thus, awareness if welfare is compromised at some level by the methods adopted in researches is paramount, likewise how the impairment can be avoided or diminished. Specific methodologies and housing conditions, such as quantitative feed restriction and housing in metabolic cages are still commonly used in nutritional trials to control feed consumption and to permit individual feces and urine collection in digestibility and metabolic studies (Cochran and Galyean, 1994). Feed restriction and/ or social isolation are also used in motivational studies (Marinković et al., 2007), and sometimes applied in farms to increase profitability by exploiting animals' compensatory gain, or even to maintain the body weight of animals kept for breeding purpose (Morand-Fehr et al., 1982; Pereira Filho et al., 2005). There are evidence of animal suffering when kept under such conditions, as shown with different species, such as rats, broilers, and pigs (Lawrence and Terlouw, 1993; Sandilands et al., 2005; Marinković et al., 2007; D'Eath et al., 2009). In these experiments, the authors have demonstrated serious alterations on their behavior, mainly regarding to activity level and the appearance of stereotypies (i.e., abnormal behavior that are repetitive and has no apparent function) which could persist throughout the entire animal's productive life (Mason, 1991). Besides, the poor welfare of experimental animals in these nutritional trials might seriously affect the reliability of the studies per se, and criticism to this issue is not novelty (Done-Currie et al., 1984; Marsden and Wood-Gush, 1986).

On the other hand, the information achieved in these nutritional trials play an important role in understanding how animals can better utilize nutrients from feed and through it minimize environment impact and reduce production costs. In vitro methods have been developed to evaluate nutrient utilization. The majority of them works well in comparing nutritional quality of feeds, however they also show plenty of limitations in accurately predict digestibility or efficiency of use (Krizsan et al., 2012). All in all, the use of animals in nutritional trials is still need and the key point is to figure out how animal handling can be improved to secure welfare integrity.

To our knowledge, there is no previous work done with goats describing how the species cope to these conditions, particularly young animals. As a highly social specie, both domestic and wild goats live in small to moderate group size. Since very young age kids form play bands of peers, with the peak of play around 10 - 14 days of age, possibly showing this level of activity up to 9 weeks of age, after that play is not seen so often (Dwyer, 2017). During these first weeks of age kids learn to eat solid food with their mothers, and also from social learning with other kids (Miranda-de 
la Lama and Mattiello, 2010). Therefore it could be expected that social and feed restriction would detriment the welfare of the goat kids. Since these restrictions are still in common use, we decided to follow a nutritional study that was already settled up. Our aim was to evaluate the welfare of goat kids submitted to specific procedures of a nutritional experiment, which included feed restriction and housing in metabolic cages. We focused on assessing their behavior and performance, with the hypothesis that feed restriction would not just impair their growth development, but compromise their welfare. Our second aim was to provide scientific basis for a general discussion on experimental procedures and the challenges that need to be addressed regarding the welfare conditions of experimental animals.

\section{Material and methods}

\section{Housing and management}

This study was approved by the Committee on the Ethical Use of Animals (Comissão de Ética no Uso de Animais - CEBEA) of the Faculty of Agricultural and Veterinarian Sciences, Universidade Estadual Paulista (UNESP) at Jaboticabal campus, under protocol number 008919-08.

The study was conducted in the Goat facilities UNESP at Jaboticabal county (São Paulo state, Brazil: 21ำ15'22" latitude S, 48ำ18'58" longitude W and $595 \mathrm{~m}$ in altitude).

Behavioral data were recorded from animals that were subjects to an animal nutritional experiment, and so the set up could not be changed by the behavioral research team, likewise the treatments and procedures that animals were submitted to. In the nutritional experiment, the researchers aimed to estimate net requirements for maintenance and digestibility of goat kids, and for that it is necessary the use of a quantitative feed restriction approach (i.e., generally one level slightly above maintenance level, approximately $1.2 \times$ maintenance; one level which animals are fed ad libitum, and intermediate levels between maintenance and ad libitum).

\section{The nutritional experiment procedures}

The goat kids were under standard experimental procedures of a nutritional experiment. Soon after birth, in the nutritional experiment, they were separated from their mothers, identified and housed in individual metabolic pens (measuring $0.50 \times 1.00 \mathrm{~m}$, and with side walls of $0.60 \mathrm{~m}$ and heighted $1.40 \mathrm{~m}$ from the floor). A feeder and a water trough were fixed in all cages. The pens were installed in a brick shed with a metal roof and with $3.0 \mathrm{~m}$ high.

In the first two days of life, the goat kids received colostrum ad libitum, and after this they began to receive goat milk ad libitum, until they reached 5 $\mathrm{kg}$ of body weight. At seven days old, the animals started to receive solid ration (50\% hay and 50\% concentrate). Milk and solid ration were offered in two equally meals per day (at 8 a.m. and 6 p.m.), and the milk using individual bottles. When they reached $5 \mathrm{~kg}$, feed restriction started for both solid ration and milk. The specific procedures for the feed restriction is explained below.

The experimental solid ration consisted of dehydrated corn plants, cracked corn grain, soybean meal, sugarcane molasses, soybean oil, mineral mixture, and calcitic limestone. All of the animals were dehorned with a hot iron soon after reaching one week of age. Three animal's categories were used in the experiment: females $(n=9)$, males $(\mathrm{n}=9)$ and castrated males $(\mathrm{n}=9)$. The male goat kids were randomly selected to be castrated, who were subjected to an orchiectomy procedure, which was carried out in the same day when they were dehorned.

\section{Feed restriction}

When animals reached $5 \mathrm{~kg}$ of body weight (17.5 \pm 5.4 days old), the nutritional experiment started and the kids were submitted to the feed restriction. They were randomly assigned to three nutritional regimes (NR), as follow: NR1, when the animals were fed ad libitum of solid food and received a maximum amount of $1.5 \mathrm{l}$ of milk/day, NR2, when the animals were intermediate restricted matchfed to NR1 (restriction of $25 \%$ of solid food and 
milk), and NR3, when the goat kids were severely restricted match-fed to NR1 (restriction of $50 \%$ of solid food and milk). The feed restriction (solid and milk) was daily calculated based in the NR1 level consumption in the previous day. The feed offered to NR1 was adjusted daily to have $15 \%$ of leftover feed from the amount provided. Animals were followed in the nutritional experiment from birth until 5 weeks old.

\section{Feed intake and performance}

Each kid was weighed at birth and then every week until 5 weeks old. The weight gains between the intervals of each period were calculated. Their feed intake of solid food and milk was daily controlled until 5 weeks old.

\section{Behavioral studies}

The behavioral observations were carried out using video cameras, which were strategically positioned above the animal's body, and they were continuously recorded 24 hours for three consecutive days. For nocturnal observations, artificial light was used. The observations were conducted by direct and continuously method, using the focal sampling method (Martin and Bateson, 1993).

\section{Pilot study}

A pilot study was conducted to identify the circadian behavioral rhythm of goat kids under these experimental conditions and define the best observational periods. The Ethogram is shown in Table 1. From the data obtained from the mean vectors in the circular analyses - applying the Rayleigh uniformity test in Oriana 2.0 (2009) -, the times exhibiting the most likely occurrence of the behavioral categories of interest were identified: $10,11,12,13,15$, and $17 \mathrm{~h}$.

After defining the observations time during the day, 27 goat kids were randomly selected to be observed (nine males, nine females and nine castrated males), for three consecutive days, totalizing 702 hours of continuous observation. It was applied the same methodology used in the pilot study, and the kids were $33.2 \pm 3$ (mean \pm SD) days old .

Table 1 - Ethogram of the goat kid's behavior observed in the experiment

\begin{tabular}{ll}
\hline Behavioral category & Description \\
\hline
\end{tabular}

Interaction with

the feed trough

Interaction with

the water trough

Self-grooming

Social interaction receiver neighboring cage.

Social interaction actor When an animal tries to make physical contact with the goat kid in the

When an animal responds to the attempt at physical contact from the goat kid in the neighboring cage by stopping the activity being performed at the time and orienting itself (with the head or entire body) toward the neighbor animal that started the interaction (actor).

Attention to humans When an animal stops its activities and diverts its attention to a human, orienting its body and head in the direction of humans. It is standing and keeps it ears erect.

\begin{tabular}{ll}
\hline Lying down & $\begin{array}{l}\text { When an animal has its four legs } \\
\text { folded, with the ventral side of the } \\
\text { body contacting the cage floor, either in } \\
\text { lateral or ventral decubitus. }\end{array}$ \\
\hline Standing & $\begin{array}{l}\text { When an animal has four legs in contact } \\
\text { with the floor without moving its body. }\end{array}$ \\
\hline Bipedal posture & $\begin{array}{l}\text { When an animal places its two front } \\
\text { legs on the cage bars or walls, keeping } \\
\text { its two hind legs on the floor; the body } \\
\text { is positioned vertically or longitudinally } \\
\text { to the floor. Not registered if performed } \\
\text { in combination with other behavior. }\end{array}$ \\
\hline Moving & $\begin{array}{l}\text { This category covers all of the walking } \\
\text { and jumping activities inside the cage. }\end{array}$ \\
\hline Interaction with the cage & $\begin{array}{l}\text { When an animal bites, licks or gnaws } \\
\text { the cage bars or any other structure } \\
\text { present in the cage (walls, feed and } \\
\text { water troughs). }\end{array}$
\end{tabular}




\section{Statistical analyses}

Data was analyzed in a randomized complete block design with a $3 \times 3$ factorial scheme, testing three nutritional regimes (NR1, NR2, NR3) and gender (males, females and castrated males). Normality was tested using Shapiro-Wilk test in the SPSS Statistical Program (v 12.1). When the residual of the data was not normally distributed, it was used a transformation $(\log . \mathrm{x}+5)$, and the means were presented using antilog (exp (log. $x)-5)$. The individual animal was considered the experimental unit and each fed-matched trio (NR1, NR2, NR3) considered as a block.

To analyze the weights and the weight gains, variance components were estimated by restricted maximum likelihood method (REML), using the first order unstructured (UN1) in the model. It was considered the effects of nutritional levels, gender, weeks of age and its interactions as fixed effects and block as random effect, taking in account the repeated measures of the weight over five weeks, using the MIXED procedure of SAS. Birth weight was included as a covariate. To estimate the weight gain per week, the weights were regressed on the weeks, using the same model described above. The regression coefficient estimated (weights on weeks) within treatment and gender were compared using orthogonal contrasts.
Behavior data (frequencies and duration) and the dry matter intake were analyzed as mixed models, using as fixed effects the nutritional levels, gender and their interactions, and the block as random effect in the MIXED procedure of SAS (version 9.1). The significance of effects was tested with the Tukey's post-hoc adjustment test. Significance was declared at $\mathrm{p} \leq 0.05$.

\section{Results}

\section{Behavior}

The frequency and the duration of several behavior categories (interaction with the feed trough, interaction with the water trough, selfgrooming, social interaction actor, social interaction receiver, bipedal posture, lying down, and moving) were affected neither by treatment nor by gender and its interaction $(p>0.05)$.

There was a significant effect of nutritional regimes on the frequency of attention to humans, in which NR3 expressed the lowest frequency of attention and no differences were shown between NR1 and NR2 (Table 2). Castrated males exhibited the lowest frequency and duration of attention to humans; however, there was no difference between males and females.

Table 2 - Ethogram of the goat kid's behavior observed in the experiment

\begin{tabular}{|c|c|c|c|c|c|c|}
\hline & Variable & NR1 & NR2 & NR3 & F Test & $\mathbf{P}$ \\
\hline \multirow{5}{*}{$\begin{array}{l}\text { Attention } \\
\text { to humans }\end{array}$} & Duration & $44.75 \pm 0.2$ & $71.13 \pm 0.2$ & $39.08 \pm 0.2$ & 2.05 & 0.16 \\
\hline & Frequency & $3.13 \pm 0.05^{\mathrm{a}}$ & $3.65 \pm 0.04^{\mathrm{a}}$ & $1.92 \pm 0.04^{b}$ & 4.32 & 0.03 \\
\hline & & Males & Females & Castrated & & \\
\hline & Duration & $76.33 \pm 0.2^{\mathrm{a}}$ & $59.27 \pm 0.2 \mathrm{ab}$ & $26.95 \pm 0.2^{b}$ & 5.87 & 0.01 \\
\hline & Frequency & $3.46 \pm 0.05^{\mathrm{a}}$ & $3.54 \pm 0.05^{a}$ & $1.73 \pm 0.05^{b}$ & 5.89 & 0.01 \\
\hline
\end{tabular}

Note: ${ }^{a, b}$ Means followed by the same letter in the rows do not differ $(p>0.05)$ by Tukey's test.

Female kids interacted with the cage for longer and for a greater number of times than males and castrated males (Table 3). It should be noted that this behavior, considered a stereotype, was exhibited by all the animals.
NR3 kids presented a significantly greater frequency and duration of the standing behavior, when compared to the other nutritional regimes. NR2 and NR1 kids did not present any difference between each other (Figure 1). 
Table 3 - Transformed means (antilog) \pm SD for the duration (seconds/hour) and frequency (occurrences/hour) of goat kids interaction with the cage according to gender

\begin{tabular}{cccccc}
\hline Variable & Males & Females & Castrated Males & F Test & P \\
\hline Duration & $325.43 \pm 0.09^{\mathrm{b}}$ & $468.85 \pm 0.09^{\mathrm{a}}$ & $295.01 \pm 0.09^{\mathrm{b}}$ & 6.35 & 0.009 \\
Frequency & $14.46 \pm 0.07^{\mathrm{ab}}$ & $17.28 \pm 0.07^{\mathrm{a}}$ & $11.99 \pm 0.07^{\mathrm{b}}$ & 3.87 & 0.04 \\
\hline
\end{tabular}

Note: ${ }^{a, b}$ Means followed by the same letter in the rows did not differ $(p>0.05)$ by Tukey's test. SD $=$ standard desviation.

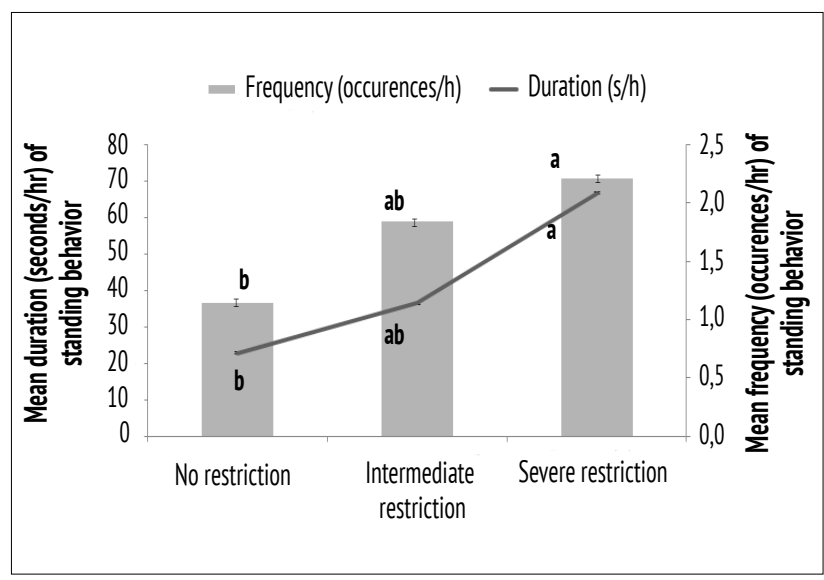

Note: ${ }^{a, b}$ Means followed by the same letter on the line do not differ $(p>0.05)$ by Tukey's test. SD = standard desviation.

Figure 1 - Transformed means (antilog) \pm SD of the duration (seconds/hour) and frequency of standing behavior (occurrences/ hour) in goat kids subjected to the different nutritional regimes

\section{Feed consumption}

As expected, the nutritional regime affected the total dry matter intake (solid diet + milk), validating that during the experiment, the restrictions were effectively $24.3 \%$ for animals in NR2 and $52.3 \%$ for animals in NR3 (Table 4), based in their own consumption.

However, there was no significant effect of nutritional regime on the solid diet dry matter intake, which shows that during this period, the real feed restriction was related to the amount of milk provided, since the animals consumed the solid feed in low rates. Besides, the solid feed intake and the total DM intake was not influenced by gender, which was also expected (Table 5).
Table 4 - Dry matter (DM) consumption ( $g /$ day; means \pm SD) of goat kids subjected to different nutritional regimes

\begin{tabular}{lccccc}
\hline PAR & NR1 & NR2 & NR3 & F Test & P \\
\hline Solid DM* $^{*}$ & $11.42 \pm 7.7$ & $4.9 \pm 1.4$ & $7.8 \pm 2.5$ & 0.79 & 0.4682 \\
Total DM $^{* *}$ & $185 \pm 9^{\mathrm{a}}$ & $139.9 \pm 4.1^{\mathrm{b}}$ & $88.2 \pm 4.6^{\mathrm{c}}$ & 59.42 & $<0.0001$ \\
\hline
\end{tabular}

Note: ${ }^{a, b}$ Means followed by the same letter on the line do not differ $(p>0.05)$ by Tukey's test. SD = standard desviation. PAR = parameters. *Solid feed DM consumption (g/day). ${ }^{* *}$ Total DM consumption (solid + milk) (g/day).

Table 5 - Solid ration dry matter consumption $(\mathrm{g} /$ day) and total dry matter consumption (solid ration + milk) by goat kids according to gender ( $g /$ day/ means \pm SD)

\begin{tabular}{cccccc}
\hline Parameters & Males & Females & $\begin{array}{c}\text { Castrated } \\
\text { Males }\end{array}$ & F Test & $\mathbf{P}$ \\
\hline SDM & $4.3 \pm 1.9$ & $10.4 \pm 7.3$ & $7.8 \pm 2.6$ & 0.02 ns & 0.27 \\
TDM & $137 \pm 3.5$ & $139.9 \pm 8.6$ & $179.8 \pm 5.8$ & 0.69 ns & 0.98 \\
\hline
\end{tabular}

Note: SDM = Solid ration DM consumption, TDM = Total DM consumption $\mathrm{SD}=$ standard desviation.

\section{Performance}

There was a significant interaction between body weight and weeks of age ( $F=21.08, \mathrm{p}<0.001)$, where NR1 presented the greatest body weights over the weeks, followed by NR2 and NR3 (Figure 2). However, these differences were not observed in the first week of age.

There was also a significant effect between body weight and weeks of age ( $F=101.41, p<0.0001)$, with NR1 having the greatest gains, followed by NR2 and NR3 (NR1 $=0.99 \mathrm{~g} \pm 0.02$; NR2 $=0.71 \mathrm{~g} \pm 0.02$; $\mathrm{NR} 3=0.37 \mathrm{~g} \pm 0.03$ average weekly gain, \pm S.E) . 
The interaction between gender and weeks was not significant $(p=0.64)$. The evolution of body weight $(F=4.74, p=0.01)$ was significant affected by gender, in which male and females shown similar body weights $(\mathrm{p}=0.99)$ and were higher than castrated kids (males $=6.47 \mathrm{~kg} \pm 0.05$; females $=$ $6.47 \mathrm{~kg} \pm 0.05$; castrates $=6.27 \mathrm{~kg} \pm 0.06$ mean body weight + SE).

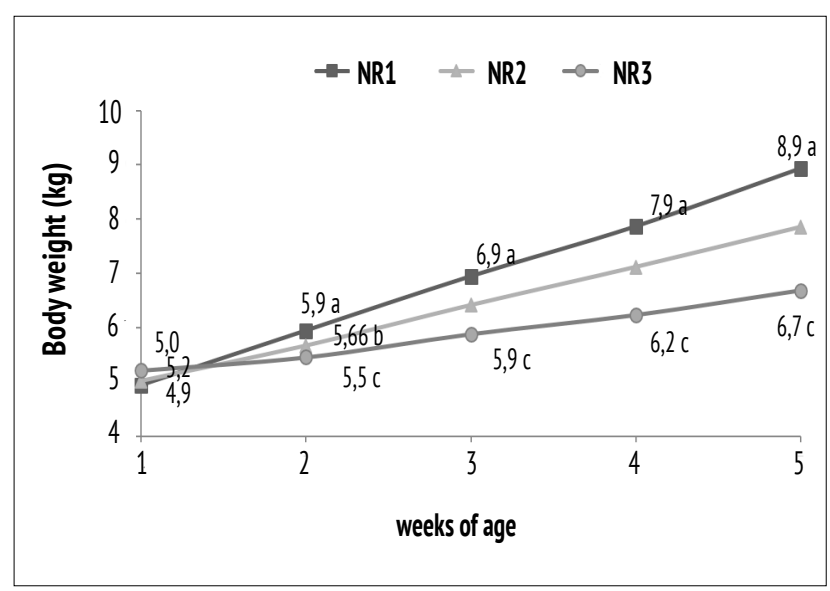

Figure 2 - Mean results of the goat kid's body weight comparing the different nutritional regimes (NR1 (ad libitum), NR2 (25\% of feed restriction) and NR3 (50\% of feed restriction) along the experiment per week..

\section{Discussion}

Our results showed that the welfare of the goat kids submitted to this nutrition trial was negatively affected, and to some extent impaired, with the appearance of stereotypies in all animals, decrease of activity and social interaction with humans, besides of a decrease in feed consumption. The severely restricted animals showed signals of apathy and female kids were engaged in stereotypical behavior more frequently than other animals. We discuss below the consequences of keeping young animals in metabolic cages for nutritional trials applying feed restriction and speculate on potential alternatives that might be considered in the future.

Severely restricted animals (NR3) presented stronger behavior indicators of a worst welfare, when compared to NR1 and NR2. In a previous study with feed restricted calves (Vieira et al., 2008), animals submitted to feed restriction presented an increase in their activity and spent more time in the feeder, and according to the authors, would be possible behavior indicators of hunger. In our study, NR2 was more active than NR1. However, no differences in the visits to the feed trough (another hunger indicator, D'Eath et al., 2009) was observed among the goat kids. Nevertheless, NR3 showed the lower activity level and frequency of attention to humans. These animals were often unresponsive to external stimuli (which were generally associated with the moment of feeding and the daily presence of humans in the stable) reinforcing the suggestion of their detrimental condition. Thus it might be that the higher level of activity used previously as an indicator of hunger (D'Eath et al., 2009) was shown by NR2, but NR3 might have exceeded this threshold.

This apathy and the absence of response to stimuli characterize a typical scenario of learned helplessness. Learned helplessness is a cognitive phenomenon that occurs due to repeated experiences in which an individual has lack of control over the results of its actions. The individual stops trying based on the belief of its inability to produce what it desires (McBride, 1984). This condition of helplessness has been shown to have long-lasting negative effects on the expression of previously learned appetitive responses, such as the consumption of palatable foods, which is linked to loss of the pleasure (Cabib, 2006), fact that might have happened to our severely restricted goat kids (NR3). The mechanism in the animal's brain involves the neurotransmitter dopamine (which is associated with reward-seeking behavior). The repeated stressful experiences induces changes such as the release of excessive dopamine in different forebrain areas. When behavioral responses fail (as in the case of uncontrollable stress), profound inhibition of dopamine release occurs in the nucleus accumbens, causing helplessness, behavioral despair, which are associated to depression syndromes (Puglisi-Allegra and Cabib, 1997; Cabib, 2006; Hall et al., 2008). One could speculate that the same mechanism might have happened to the severely restricted goats in this study.

Besides of the learned helplessness scenario, which per se is considered dysfunctional and 
pathological, (Cabib et al., 2006) the prolonged inactivity shown by NR3 can also be considered an abnormal behavior. According to Wiepkema et al. (1983), maintaining static posture while sitting, standing or lying down for a long period of time have been reported as an abnormal behavior and should be avoided in any experimental set up. Many factors may affect the degree of activity, but it is observed that confined animals are often less active, especially when they are in a restricted space. The amount of time that these animals are inactive has been used to indicate a state of boredom (Wemesfelder, 1984). According to Broom and Johnson (1993), inactive animals might be exposed to a higher level of suffering, although it is difficult to determine whether reduced activity indicates reduced animal welfare. However, reduced activity combined with a lack of responsiveness to external stimuli can be characterized as depression (Wiepekma et al., 1983; Fraser, 1984). Depressed animals generally exhibit a decrease in their behavioral repertoire, with a decrease in maintenance behaviors - i.e. reactivity, ingestion, exploration, movement, association to peers, body care, territorialism and rest (Fraser 1983)-, deterioration of social behavior, and an increase in abnormal behaviors (Fraser, 1988). Some of these conditions were indeed observed in some individuals in the present experiment, which suggests a poor welfare.

Another element that supports the hypothesis of deterioration in the welfare was the stereotypies shown in all goat kids, regardless of the nutritional regime or gender. According to Broom and Fraser (2010), stereotypies occur in situations in which animals do not have control over their environment or when events are unpredictable. It can be explained in terms of sustained attempts to perform a highlymotivated behavior pattern that are prevented by the captivity (Rushen and Mason, 2006). To be linked to poor welfare, stereotypies should be associated with signals of stress, fear or depression, or shown in situations proved to be deficient (by a preference test, for instance). However according to Mason and Latham (2004) the relationship between stereotypies and poor welfare is not always straight-forward. There are circumstances in which stereotypies might be linked to good or neutral welfare as well as poor welfare; for instance beneficial effects shown from performing the specific-source of the stereotypy (do-it yourself enrichment), or arising from utter repetition (mantra effects). So according to them, to use stereotypies in welfare assessments, more information should be gathered to help the interpretation of the context that the animals are inserted. But overall stereotypies are a signal of potential suffering and should always be taken seriously.

Because the females expressed stereotypies more strongly, it is relevant to consider the hypothesis that they are more susceptible to stress factors present in the experimental conditions or are more likely to develop this type of behavior when exposed to adverse conditions. According to Faraday (2002), gender is a main factor that influences different vulnerabilities to stress; when subjected to a stressor, males and females exhibit distinct physiological and behavioral responses, such as different epidemiological patterns of stressrelated diseases (Frankenhaeuser et al., 1976). In humans, gender has been explored in psychological studies that show a greater disposition of females to develop cases of depression (Palanza, 2001).

The early experience with humans by negative interactions, such as the castration, could also have affected the goat kids. Castrated males were less interested to human contact comparing to female and males. Besides, the castrated kids presented the lower average body weight, what could be another indicator of a worse welfare. Studies have demonstrated that animals are able to discriminate between humans based on previous experiences. For instance, Miura et al. (1996) reported that pigs fed by the same handler for two weeks in a field test went directly to that handler and avoided a stranger. Cows also maintain a greater distance from a hostile handler than a gentle one (Munksgaard et al., 2001), and calves treated positively and negatively recognized the respective handlers and reacted by searching for the gentle handler but were not able to identify them when relocated to a new environment (Passillé et al., 1996). The same effects were observed with young pigs (Koba and Tanida, 1999).

The impairment on their welfare might have been also extended to their feed consumption. The dry matter intake of solid diet was lower (11.4 g/day on average for NR1) of what would be 
expected for kids at the same age and under similar rearing conditions, which would be an average dry matter intake of at least 30 to $40 \mathrm{~g} \mathrm{DM} /$ day of solid diet (Morand-Fehr, 1981; Ramos et al., 2004). Furthermore, it was expected a significant effect of nutritional regime on the solid diet dry matter intake, once the feed restriction would stimulate the earlier solid diet intake to overcome the nutritional deficits, as it has been previously reported (Graham, 1982).

During this nutritional trial, the goat kids were kept in metabolic cages, which could have reduced their consumption. It's known in the literature that visual contact is an extremely important factor in learning processes, in early stages of life, and it is fundamental in linking the process of learning by imitation, or "social facilitation" (McFarland, 1982; Alcock, 1993), which is defined as an evolutionary strategy that plays a vital role in the survival of species. As the metabolic cages did not permit a direct visual contact among the kids, this may have influenced the delay of an effective solid diet intake by the animals.

But on the other side, as the information obtained from metabolism trials is still very important for farmers and industry, alternative methods for estimating digestibility and efficiency of use should be developed requiring less use of animals. For several decades researches have suggested alternative methods (i.e., analytical, in vitro) for this purpose, the majority of them show various limitations, but the most important of them is their low accuracy (i.e., low predictability of in vivo results), besides the establishment of novel methods still requires the comparison to in vivo responses (i.e., golden standard). At the end of day it means that in addition of developing novel methods there will always be the need of improving animal handling in vivo studies, therefore assembling guidelines meeting animal welfare are crucial. Some possibilities of improving animal handling are: 1) housing group of animals, which support the social interaction among animals (Haer and Vries, 1993); 2) use of automatic feeders that allow the identification of the animal in the feeder (Russell, et al., 2016); 3) use of cage that have side walls that are half height, allowing visual contact between animals; 4) using large pens for housing animals, similar to what has been used in beef cattle studies (Fiorentini et al., 2015); 5) environment enrichment in the cage (Ceballos, et al., 2016); 6) allow periods of socialization; among others.

We have shown in this study that in general the goat kids submitted to feed restriction and housed in metabolic pens did not have much of a control over their environment, a condition that might have serious consequences on different aspects of their lives, including the development of apathy and learned helplessness (Hosey, 2005). To alleviate the effects of this lack of control, some researchers have tried to implement the consumer-demand approach, which is a framework that animals have the opportunity to choose about certain aspects of their lives, for instance to socialize or to participate in training (Schapiro and Lambeth, 2007). Apparently to give animals the opportunities to choose within the confines of captivity increases their welfare status, giving them back some control over their lives. Another option that has been applied is the environmental enrichment. Defined as the addition of biologically relevant features for captivity animals to foster natural behaviors (Newberry, 1995), it has been widely applied in different species and might contribute to reduce boredom, increase stimuli to perform natural behaviors and potentially reduce stereotypies (Newberry, 1995; Mason and Latham, 2004).

Although it seems obvious, the amount of time housed in a restrictive space as a metabolic cage can also be consider as a major constraint on kids welfare. According to Gunn and Morton (1995) who have studied the behavior of rabbits in laboratory cages, the confinement of the metabolic cage obliges animals to have no exercise, be socially excluded from its peers and sometimes even tethered. However even with this restriction, they should be able to stand, lie down and stretch. They do not recommend animals to be housed in such condition for no longer than 14 days (including the adaptation period). In this experiment the goat kids were housed intermittently for five weeks, although they did have space to move around and stretch. A more general discussion involving standardization on international regulations of experimental procedures might be an important topic to be considered within the scientific community. 


\section{Conclusion}

As a first study evaluating goat welfare in nutritional trials, we showed that kids' welfare was compromised during the nutritional experiment, in which all animals developed stereotypes and some individuals showed signals learned helplessness. We highly encourage alternative methods to be used in digestibility studies that focus more in meeting experimental animal welfare requirements.

\section{Acknowledgments}

We would like to thank Dr. Mateus JR Paranhos da Costa for his valuable participation in this research.

\section{References}

Alcock J. Animal Behavior: An Evolutionary Approach. 5th ed. Sunderland: Sinauer Associates; 1993.

Broom DM, Fraser AF. Comportamento e bem-estar de animais domésticos. 4th ed. Barueri: Manole; 2010.

Broom DM, Johnson KG. Stress and Animal Welfare. 1st ed. London: Chapman \& Hall; 1993.

Cabib S. The neurobiology of stereotypy II: the role of stress. In G Mason, J Rushen (eds.). Stereotypic animal behaviour: fundamentals and applications to welfare. 2nd ed. Wallingford: CABI; 2006. p. 227-55.

Ceballos MC Góis KCR, Carvalhal MVL, Costa FO, Costa MP. Environmental enrichment for rabbits reared in cages reduces abnormal behaviors and inactivity. Cienc Rural. 2016;46(6):1088-93.

Cochran RC, Galyean ML. Measurement of in vivo forage digestion by ruminants. In: Fahey GC. Forage Quality, Evaluation, and Utilization. Madison: ASA, CSSA, SSSA; 1994. p. 613-43.

D’Eath RB, Tolkamp BJ, Kyriazakis I, Lawrence AB. Freedom from hunger and preventing obesity: the animal welfare implications of reducing food quantity or quality. Anim Behav. 2009;77(2):275-88.
Donne-Currie JR, Hecker JF, Wodzicka-Tomaszewska M. Behavior of sheep transferred from pasture to an animal house. Appl Anim Behav Sci. 1984;12(1-2):121-30.

Dwyer C. The behaviour of sheep and goats. In: Jensen $\mathrm{P}$ (ed.). The ethology of domestic animals: an introductory text. Wallingford: CABI; 2017. p. 161-76.

Faraday MM. Rat sex and strain differences in responses to stress. Physiol Behav. 2002;75(4):507-22.

Fiorentini G, Carvalho IPC, Messana JD, Canesin RC, Castagnino PS, Lage JF, et al. Effect of Lipid Sources with Different Fatty Acid Profiles on Intake, Nutrient Digestion and Ruminal Fermentation of Feedlot Nellore Steers. Asian-Australas J Anim Sci. 2015;28(11):1583-91.

Frankenhaeuser M, Dunne E, Lundberg U. Sex differences in sympathetic-adrenal medullary reactions induced by different stressors. Psychopharmacology (Berl). 1976;47(1):1-5.

Fraser AF. The behaviour of suffering in animals. Appl Anim Behav Sci.1984;13(1-2):1-6.

Fraser AF. Animal Suffering: The appraisal and control of depression and distress in livestock. Appl Anim Behav Sci. 1988;20(1-2):127-33.

Fraser D, Weary DM, Pajor EA, Milligan BN. A scientific conception of animal welfare that reflects ethical concerns. Anim Welf.1997;6:187-205.

Graham NM. Maintenance and Growth. In: Coop IE. Sheep and goat production. Amsterdam: Elsevier Scientific Pub Co.; 1982.

Gunn D, Morton DB. Inventory of the behaviour of New Zealand White rabbits in laboratory cages. Appl Anim Behav Sci. 1995;45(3-4):277-92.

Haer LCM, Vries AG. Feed intake patterns of and feed digestibility in growing pigs housed individually or in groups. Livest Prod Sci. 1993;33(3-4):277-92.

Hall C, Goodwin D, Heleski C, Randle H, Waran, N. Is there evidence of learned helplessness in horses? J Appl Anim Welf Sci. 2008;11(3):249-66. 
Hosey GR. How does the zoo environment affect the behaviour of captive primates? Appl Anim Behav Sci. 2005;90(2):107-29.

Koba Y, Tanida H. How do miniature pigs discriminate between people? The effect of exchanging cues between a non-handler and their familiar handler on discrimination. Appl Anim Behav Sci. 1999;61(3):239-52.

Krizsan SJ, Nyholm L, Nousiainen J, Südekum KH, Huhtanen P. Comparison of in vitro and in situ methods in evaluation of forage digestibility in ruminants. J Anim Sci. 2012;90(9):3162-73.

Lawrence AB, Terlouw EM. A review of behavioral factors involved in the development and continued performance of stereotypic behaviors in pigs. J Anim Sci. 1993;71(10):2815-25.

Marsden D, Wood-Gush DGM . A note on the behavior of individually penned sheep regarding their use for research purposes. Anim Sci. 1986;42(1):157-9.

Marinković P, Pesić V, Loncarević N, Smiljanić K, Kanazir S, Ruzdijić S. Behavioral and biochemical effects of various food-restriction regimens in the rats. Physiol Behav. 2007;92(3):492-9.

Martin B, Bateson P. Measuring Behavior: An introductory guide. UK: Cambridge University Press; 1993.

Mason GJ. Stereotypies: a critical review. Anim Behav. 1991;41(6):1015-37.

Mason GJ, Latham NR. Can't stop, won't stop: is stereotypy a reliable animal welfare indicator? Anim Welf. 2004;13(Suppl 1):S57-69.

McBride G. Feral animal studies in animal science: The uses and limitations of feral animal studies on contemporary animal science. J Anim Sci. 1984;58(2):474-81.

McFarland D. The Oxford Companion to Animal Behavior. Oxford: Oxford University Press; 1982.

Miranda-de la Lama GC, Mattiello S. The importance of social behaviour for goat welfare in livestock farming. Small Rumin Res. 2010;90(1-3):1-10.
Miura A, Tanida H, Tanaka T, Yoshimoto T. Behavioral Response to humans of weanling pigs exposed to a short period of individual handling. Anim Sci Technol. 1996; 67(8):693-71.

Morand-Fehr R. Goat production. London: Butterworths; 1981.

Morand-Fehr P, Hervieu J, Bas P, Sauvant D. Feeding of young goats. Proceedings of the 3rd International Conference on Goat Production and Disease; 1982 Jan 10-15; Tuscon, Arizona. Scottsdale, Arizona: Dairy Goat Journal Pub Co.; 1982. p. 90.

Munksgaard L, Passilé AM, Rushen J, Herskin MS, Kristensen AM. Dairy cows' fear of people: social learning, milk yield and behavior at milking. Appl Anim Behav Sci. 2001;73(1):15-26.

Newberry RC. Environmental enrichment: Increasing the biological relevance of captive environments. Appl Anim Behav Sci. 1995;44(2-4): 229-43.

Oriana 2.0. Kovach Computing Services; 2009 [cited 2018 Jan 29]. Available from: http://www.kovcomp.com.

Palanza P. Animal models of anxiety and depression: how are females different? Neurosci Biobehav Rev. 2001;25(3):219-33.

Passillé AM, Rushen J, Ladewig J, Petherick C. Dairy calves' discrimination of people based on previous handling. J Anim Sci. 1996;74(5):969-74.

Pereira Filho JM, Resende KT, Teixeira IAMA, Silva Sobrinho AG, Yáñez EA, Ferreira ACD. Effect of dietary restriction on the productive and economic performance of F1 Boer x Saanen goats. R Bras Zootec. 2005;34(1):188-96.

Puglisi-Allegra S, Cabib S. Psychopharmacology of dopamine: The contribution of comparative studies in inbred strains of mice. Prog Neurobiol. 1997;51(6):637-61.

Ramos JLF, Costa RG, Medeiros AN. Productive performance of goats subjected to different periods of suckling. R Bras Zootec. 2004;33(3):684-90. 
Rushen J, Mason G. A decade-or-more's progress in understanding stereotypic behaviour. In: Mason G, Rushen J (Eds.). Stereotypic behaviour: fundamentals and applications to welfare. Wallingford: CABI; 2006. p. 1-18.

Russell JR, Sexten WJ, Kerley MS. Effect of corn inclusion on soybean hull-based diet digestibility and growth performance in continuous culture fermenters and beef cattle. J Anim Sci. 2016;94(7):2919-26.

Sandilands V, Tolkamp BJ, Kyriazakis I. Behaviour of food restricted broilers during rearing and lay effects of an alternative feeding method. Physiol Behav. 2005;85(2):115-23.

Schapiro SJ, Lambeth SP. Control, choice, and assessments of the value of behavioral management to nonhuman primates in captivity. J Appl Anim Welf Sci. 2007;10(1):39-47.
Vieira AP, Guesdon V, Passillé AM, von Keyserlingk MAG, Weary DM. Behavioural indicators of hunger in dairy calves. Appl Anim Behav Sci. 2008;109(2-4):180-9.

Wiepkema PR, Broom DM, Duncan IJH, van Putten G. Abnormal behaviours in farm animals. Brussels: A report of the Commission of the European Communities; 1983.

Wemelsfelder F. Animal boredom: Is scientific study of the subjective experiences of animals possible? In: MW Fox, LD Mickley (eds.). Advances in Animal Welfare Science. Leiden: Martinus Nijhoff Publishers; 1984. p. 115-54. 